\title{
A TRANSMISIÓN EN CANTARES GALLEGOS. UNHA POETICA DA ORALIDADE E DA INICIACIÓN
}

Mariela Paula Sánchez ${ }^{1}$

Instituto de Investigaciones en Humanidades y

Ciencias Sociales (Universidad Nacional de La

Plata-CONICET)

doi:10.17075/rcsxxi.2014.061

\section{CONSELLO}

DA CULTURA

GALEGA

1 Agradézolle moi especialmente á profesora Carme Pazos a súa lectura do texto e as suxestións gramaticais que, sen dúbida, implicaron unha notoria contribución á versión definitiva desta proposta de análise. 

O problema do noso destino, do noso común destino de homes, ¿non foi tratado sempre?, ¿̇non é tratado agora?, ¿̇non será tratado mañá? Cando non esista a vida, poderemos nos despreocupar da vida; cando non esista a morte, poderemos nos descoidar da morte. Mais mentras esistan a vida e a morte -é decir, mentras esistamos nós-, ises dous lados do ángulo do noso ser [...] serán, nunha forma ou noutra, temas naturás i eternos da nosa meditación.

O mesmo acaece coas grandes obras do esprito humán.

(Ricardo Carballo Calero, Contribución ao estudo das fontes literarias de Rosalía. Discurso de ingreso na Real Academia Galega)

\section{ACHEGAS E SUBSTRATOS CONCEPTUAIS PARA UN TRATAMENTO DA TRANSMISIÓN}

A transmisión é unha modalidade incorporada ao textual que xeralmente ten máis cabida —ou tena dun modo máis evidente— nun contexto narrativo que nun soporte lírico. Para considerar esa modalidade e para vencer os compartimentos estancos da clasificación dun determinado soporte, é viable adoptar unha ancoraxe conceptual relacionada coa antropoloxía social e cultural. Para unha análise de Cantares gallegos que considere este tipo de mirada, é pertinente tamén ter en conta que o texto pode pensarse como produto histórico que ten a súa orixe na expansión dos primeiros paradigmas científicos de compilación etnográfica, e que o traballo de campo feito por Rosalía de Castro e por Manuel Murguía para escolmar os cantares populares galegos sostén a continuidade dunha ollada antropolóxica que deixa un terreo fértil para outro tipo de achega con algúns puntos de contacto no tratamento.

Unha mirada que non se pode botar de lado en materia de estudo da transmisión é a xa clásica — pero digna sempre de volver ser visitada — de Walter Benjamin en «El narrador», na súa análise do retorno enmudecido do campo de batalla:

El narrador toma lo que narra de la experiencia, sea la propia o una que le ha sido transmitida. Y la transmite como experiencia para aquellos que oyen su historia. El novelista, en cambio, se ha aislado. El lugar de nacimiento de la novela es el individuo en su soledad, que ya no 
puede referirse, como a un ejemplo, a los hechos más importantes que lo afectan; que carece de orientación y que no puede dar consejo alguno (Benjamin 1986: 193).

O narrador oral ao que se refire Benjamin, o narrador que convoca a quen o escoita ao redor do lume, está entón lonxe da figura illada do novelista, pero achégase bastante, nalgún senso, a certas decisións estéticas dos poetas. Nas escenas de transmisión susceptibles de ser rastreadas en Cantares gallegos, nas súas pasaxes narrativas portadoras de niveis discursivos que albergan algunha instancia de aprendizaxe ou de intento de toma de conciencia, no xesto de facer abrir os ollos sobre unha dura realidade posta en literatura por Rosalía de Castro, emerxe ese narrador artesán, ese transmisor que, como o oleiro — parafraseando a comparación que estabelece Benjamin — dá forma oral á materia da experiencia ${ }^{1}$. Walter Benjamin vén a conto para botar luz sobre ela, nesta lectura distanciada, e posibilita que repensemos a súa permeabilidade analítica e os diferentes camiños de acceso que aínda podemos percorrer, malia as múltiples lecturas que se fixeron do libro de Rosalía ${ }^{2}$.

Volvendo a esta exploración dunha achega teórica focalizada na transmisión, ante a inminencia dos períodos traumáticos que deron pé a que o relato se fixese máis curto, o pensador alemán advirte:

En realidad sucedió que el hombre de hoy logró inclusive abreviar el relato. Tenemos la evolución de la short story, del cuento, que se ha desprendido de la tradición oral y que ya no permite esa lenta acumulación de capas finísimas y transparentes que es la metáfora más adecuada para referirse al modo en que la narración perfecta aparece como estratificación de los relatos de muchas noches. (Benjamin 1986: 197).

1 Neste senso, cabe recordar a xa clásica apreciación de Ricardo Carballo Calero acerca de que, en Cantares gallegos, Rosalía «inspirouse direitamente na poesía popular e na vida de Galicia, e atopóu molde propio para espresar o que se propuña» (Carballo Calero 1952: 25) e que "N-íles [é dicir, en Cantares gallegos] Rosalía identifícase prenamente co pobo galego» (Carballo Calero 1952: 26).

2 Dolores Vilavedra e María do Cebreiro Rábade sosteñen que «os avances futuros nos estudos rosalianos [...] deben producirse, en primeiro lugar, afondando na súa internacionalización, condición que, por outra banda, é intrínseca á propia historia do rosalianismo e os seus fitos» (Vilavedra e Rábade 2012: 14). A hipótese de lectura que se presenta aquí aspira a integrarse na liña de crebar barreiras xeográficas e epistemolóxicas para aproveitar aquelas ferramentas que as diversas disciplinas poden tender cara á literatura, coa debida atención de non sacrificar a especificidade. 
Estas consideracións atopan necesaria unha posta en correlación con outro par conceptual benjaminiano, o de «información-narración». A poesía de Rosalía de Castro encontra espazo para dar conta de historias de carácter local, que escapan do vertixinoso da información, esa forma de comunicación que Benjamin, en «El narrador», identifica como estraña á narración:

[C]on el dominio constituido de la burguesía, entre cuyos instrumentos más importantes, en la etapa del alto capitalismo, debe contarse a la prensa, aparece una forma de comunicación que $[\ldots]$ nunca había influido de manera determinante sobre las formas épicas. Pero actualmente sí lo hace. Y sucede que esa forma de comunicación no sólo es más extrańa a la narración, sino que es mucho más peligrosa para la narración que para la novela, a la cual, con todo, conduce a una crisis. Esa nueva forma de la comunicación es la información. (1986: 194).

Ese aforro de forzas da narración é unha loita contra o carácter efémero da información:

La información tiene su premio en el instante en que era $[s i c]$ fresca. Sólo vive en ese instante, debiendo entregarse completamente a él y explicarlo sin pérdida de tiempo. Otra cosa pasa con la narración; ésta no se entrega completamente. Guarda recogidas sus fuerzas y es capaz de desarrollarse luego de mucho tiempo. (Benjamin 1986: 195).

O texto de Rosalía permite a coidada acumulación de capas finísimas e transparentes propias dun narrador xa desde a cesión de voces coa que se inaugura Cantares gallegos, unha voz que delega e que permite unha continuidade que non está en débeda coa velocidade da información. Ofrécense, deste modo, ocasionais emerxencias dun/ha «narrador/a» (ou de varios narradores e narradoras) nas voces poéticas que aconsellan, recomendan ou alertan sobre algunha cuestión. Agora ben, poderiamos caer no perigo de volver sobre pasos analíticos xa explorados. A transmisión oral xa foi dabondo estudada no senso da rastreadura textual que supón recuperar as fontes orais que constitúen a materia prima rosaliana, o disparador poético das estrofas glosadas, que medran e se metamorfosean en cada un dos poemas do libro. Xa Antonio Carreño, por exemplo e como fonte que non se pode descońecer, utilizara o sintagma «transmisión oral» (Carreño 1986: 192) neste senso no seu traballo 
«El discurso de la tradición: los Cantares gallegos de Rosalía de Castro». O recorte que aquí presentamos está moito máis axustado a unha realidade textual intrínseca e non aspira de ningún modo a estudar a transmisión no marco da tradición oral, ou sexa, a transmisión dos diversos formatos que operaron como motivo dos cantares rosalianos. A presente proposta está, sen dúbida, en débeda cunha abordaxe que se desprende da mencionada «acumulación de capas finísimas» que xorden da cita de Benjamin e que conduce, por exemplo, a contemplar a análise de alguén como Arcardio López-Casanova no seu estudo das diferentes actitudes líricas na construción poemática de Cantares gallegos. Por suposto que el tamén parte da «especial naturaleza del libro, glosa de cantar, creación de una epopeya popular, formas líricas de la estampa, la escena o el episodio, etc.» (López-Casanova 1995: 51) e volve con iso ás fontes, e particularmente a Carreño, de quen fai obviamente un recoñecemento explícito:

Muy acertadamente A. Carreño subraya «la frecuencia de "cantares" estructurados a base de monólogos (el cantar-cuento), de monólogo-diálogo (el cantar-escena), de breves preguntasrespuestas» (el cantar-diálogo). (López-Casanova 1995: 51).

Faino, porén, en nota ao pé, porque a súa focalización pasa por propoñer outro esquema, que non anula a clasificación anterior, pero que fai máis evidentes as zonas de pasaxe, as pontes das voces que conviven nos poemas. Cito, in extenso, esta proposta só como antesala do enfoque ao que pasarei logo e que consistirá propiamente nas escenas puntuais ás que nos podemos achegar por estes pasos teóricos. A clasificación de López-Casanova é esta:

1. Presencia de un yo escénico enmarcador, cuando el autor implícito a modo de prólogo y epílogo da voz a un personaje caracterizado, marcado (la «menińa gaiteira»).

2. Esa «menińa gaiteira» pasa luego, consecuentemente, a ser voz presentadora o narradora poemática de algunos cuadros o estampas, por ejemplo de la romería de Nuestra Señora de la Barca [6], o retratos de tipos como el «repoludo gaiteiro» [8].

3. Este hablante puede dar voz, a su vez — y quedar entonces al margen—, a determinados personajes. Es el caso de [7], cuando la muchacha aldeana cuenta desde su primera persona la diversión de la «muiñada». 
4. En ocasiones, aparece un diálogo escénico, esto es, dos personajes componen una escena mediante el desarrollo de un diálogo. Un ejemplo modélico está en [4] con la conversación y despedida de los amantes a la hora del alba.

5. Hay apóstrofe escénico cuando un personaje — siempre marcado o diferenciado de algún modo, bien por señal o contexto— focaliza su palabra hacia un «tú» (excitador, confidencial, etc.), mero límite de la apelación. Así, cuando en [12] el enamorado — con fina delicadeza y ternura - se dirige a la amada ingrata.

6. En dos ocasiones — [...] poemas $[11,33]$ — el yo escénico de base (i.e. la «meniña gaiteira») desaparece y queda, ahora, la voz del hablante lírico.

(López-Casanova 1995: 51-52).

É pertinente citar esta sistematización de forma extensa porque dá conta da complexidade do tratamento das voces dun xeito organizado e claro, que recoñece a tradición de lectura anterior e pola súa vez dá un paso máis alá. Agora ben, hai algún que outro espazo ao que convén prestarlle especial atención ou que, polo menos, desde algúns intereses de lectura concretos ten unha fertilidade que non debemos deixar de lado. $\mathrm{O}$ que López-Casanova indica como «mero límite de la apelación» pode ser máis que iso se o consideramos cunha certa autonomía analítica. $\mathrm{O}$ marco do confidencial, pensado no marco da transmisión oral poetizada/ ficcionalizada, ten moito máis que un referente necesario desde o formal na segunda persoa do singular que se convoca. Despois desta clasificación, López-Casanova pasa á consideración de Follas novas e de En las orillas del Sar. Recoñecendo a significativa contribución do poeta e estudoso citado, e expandindo as súas hipóteses desde outro marco argumental, paga agora a pena indagar un pouco máis nos recunchos de oralidade e transmisión cunha mostra que é produto dunha selección dalgúns poemas de Cantares gallegos que, a cento cincuenta anos da súa publicación, seguen a achegar orixinalidade para estes terreos de análise.

\section{AO FÍO DA VOZ POÉTICA: «INTERLOCUTORES» QUE SON MÁIS QUE UN MERO LÍMITE DA APELACIÓN}

Preséntase en varios poemas de Cantares gallegos a posta en cuestión do lugar do saber como algo unidireccional, aspecto en que son moi significativas as mudanzas 
producidas ao redor dun eixe de voz poética e a presenza de diferentes interlocutores. Tentarase ofrecer, a continuación, unha sinalización e a conseguinte análise da presenza de núcleos en que hai unha posibilidade de rastrexar cuestións de transmisión moi particulares que botan man da creación para vehicular os reclamos, as carencias e os sentimentos en Cantares gallegos. Suponse que, para transmitir, antes hai que comunicar. Esa condición está contemplada na medioloxía ${ }^{3}$, pero cómpre resaltar que, ocasionalmente, pode chegar a haber intentos de transmisión sen que exista unha acabada comunicación previa, como se observa nalgúns poemas de Cantares gallegos, nos que se dan interesantes casos dalgunhas comunicacións frustradas. Nesas frustracións, nesas interrupcións, o que destaca é unha falta, algo que indica que, por un xesto de rebeldía, pola interposición dunha mirada renovada e lúcida ou pola entrada en escena do sobrenatural, as comunicacións non prosperan dun modo prototípico.

O foco desta lectura estará posto nalgúns núcleos de transmisión que se poden ler baixo a luz de reflexións teóricas recentes —ou, polo menos, das últimas dúas décadas - como a mencionada, pero que dan conta dun matiz máis da continuidade rosaliana como materia de análise e da capacidade de repensar os seus Cantares gallegos ${ }^{4}$ co disparador de novas ferramentas. Cómpre indicar, ademais, que a selección dos núcleos de transmisión non se estende a máis poemas porque a

3 A aparente superposición que pode haber sen a debida precisión crítica entre os conceptos de «transmisión» e «comunicación» merece algunha observación de base que nos leva a apelar a un par dicotómico do campo da antropoloxía: «La mediología establece una diferencia entre transmitir y comunicar. La acción de transmitir la define como todo aquello que atañe a la dinámica de la memoria colectiva. Al contrario de comunicar, que atañe a la circulación de mensajes dentro de una temporalidad restringida. Transmitir, en términos de mediología, consiste en transportar una información en el tiempo, entre esferas espaciotemporales diferentes. Mientras que comunicar consiste en transportar una información en el espacio, al interior de una misma esfera espacio-temporal» (Burgos 2002: 4). Elizabeth Burgos Debray alude aquí ao enfoque que se ocupa da transmisión desde a antropoloxía. En gran parte, no noso enfoque subxace esa concepción, pero, posto que non nos axustamos exclusivamente e en todos os seus aspectos a esta corrente antropolóxica, prefírese falar de transmisión nun sentido amplo. A medioloxía consiste en estudar o que o home transmite.

4 Todas as citas textuais de Cantares gallegos corresponden á edición detallada na bibliografía. Indicarase, logo da transcrición dos versos, a abreviatura CG e o número de páxina. Escóllese a edición de María Xesús Lama pola súa atención dos problemas específicos que presenta o texto para a súa fixación e porque bota man das particularidades de decisións anteriores, dos erros cometidos, pero fundamentalmente das edicións modernas nunha documentada e fluída constatación e apropiación crítica. Pola súa vez, resulta funcional traballar cunha organización do texto que ten criterios que apuntalan a análise textual cunha apelación mesurada ás cuestións máis técnicas. 
escolla estivo motivada pola proclividade a unha óptica da transmisión da experiencia que potencia as consideracións que se poden facer en Cantares gallegos sobre a vantaxe —-máis ou menos evidente de acordo co caso — concedida á mocidade no intercambio de coñecemento interxeracional ou, polo menos, ás posibilidades de poñer en cuestión unha transmisión unidireccional e previsible, baseada no acervo de experiencia directamente como algo acumulativo.

Xa desde o comezo, temos un cadro en que a transmisión está na base do legado que se lle encarga á menińa. No poema 1 (CG 131-139), o primeiro que se declara é o mandato da expresión polo medio do canto, que é fundamentalmente un mandato para a transmisión. Nun plano opera o discurso referido, polo que se reclama o canto da moza nun pedido que pasa, gradualmente, por un avance que vai do máis básico para a mantenza ata chegar ao plano divino, atravesando instancias intermedias dignas de atención. $\mathrm{O}$ incentivo inicial dáse nun ton máis ben manso, como confiado no seu efecto. Ofrécense algúns alimentos básicos. Están nun primeiro termo os zonchos, que veñen da estrofa que se glosa e da que nace o poema, e seguen os bolińos do pote e a proia da pedra do lar. A «oferta» vai gañando en sofisticación non porque as primeiras mencións non trouxesen traballo e deleite, senón porque nun segundo momento aparecen certos agregados que fan máis completa a presentación (papiñas con leite, sopiñas con viño, torrexas con mel, CG 132). É dicir, que agora o ton da solicitude medra co aditamento de incluír, xunto coa materia principal, algo que a faga máis saborosa ou substanciosa. Finalmente, podemos recońecer un terceiro paso en que a oferta vai un pouco máis alá xa que o produto que se lle promete á meniña gaiteira pode ter sabor a outra cousa, o que se ofrece é algo máis; a materia non é só o que vemos: «patacas asadas / con sal e vinagre, / que saben a noces» (CG 133). Esta aparente digresión inicial na análise non é un intento de indagarmos neste traballo en materia de alimentos en Cantares gallegos, que ben pode ser un aspecto que ten ocasión de dicir moito sobre cuestións culturais e da vida diaria na literatura 5 . A consideración dese aspecto é, máis ben,

5 E que admitiría, por exemplo, unha lectura diacrónica na que considerar un corpus que vaia desde as Cantigas de Santa María ata os nosos días xa que a cuestión da mantenza ten moito para dicir no ámbito da creación literaria, hipótese formulada sucintamente coa presentación «Cocina gallega en su tinta. Algunas incursiones de escritores de Galicia en torno a la comida» no marco da xornada «Literatura y alimentos. Cuando se nos hace agua la letra» no Centro Cultural de Espańa en Bos Aires. Vídeo dispoñible en http:// www.ustream.tv/recorded/31554823 (00:08:58/00:30:21). 
un mecanismo viable para abordar o tema da transmisión xa que está no xermolo dunha modalidade discursiva que atravesa o libro ${ }^{6}$.

O crescendo, a intensificación que acompañará a progresiva profundidade de Cantares gallegos, está xa perfilado na primeira parte do poema inaugural. As promesas pasarán logo do plano dos alimentos á «materia téxtil», dándose a opción de que quen recibe a demanda aínda considere se o quere facer ou non ("Canta, si queres», CG 133), para finalmente facer a solicitude explícita porque, malia que o ton do pedido está a dominar toda a parte I, o verbo «pedir» é explícito só nas dúas últimas estrofas («che pido que cantes» aparece dúas veces, CG 133). Súmase a isto a referencia obvia de que a derradeira solicitude sexa "por Dios» (CG 133). O que segue é un declarado exercicio de transmisión. A rapaza é a encargada do discurso lírico, a petición dunha voz poética que lle delegou a quenda. O suxeito que lle brinda esa responsabilidade (que leva ao comezo as rendas da primeira persoa gramatical) é unha instancia só aludida logo nunha xenérica terceira persoa dun plural impersoal e pola súa vez moi inclusivo («Así mo pediron», CG 134). O feito de cantar a Galicia é enunciado como un pedido que é tamén unha esixencia, porque o que ao comezo é un pedido logo alberga a obriga moral: «Que así mo pediron, / que así mo mandaron», CG 137; "Que así mo mandaron / que así mo dixeron», CG 138. Da solicitude á aserción, pasando polo clímax do mandato.

A transmisión que se inicia tamén se irá intensificando, pero grazas a un mecanismo de ampliación de interlocutores: das meniñas aludidas antes ( Xa canto, meniñas. / Coidá, que comenzo», CG 138), a voz feminina que enmarca os cantares ábrese ao pobo nun senso amplo en xénero e idade («Buscáime, rapazas, / velliñas, mociños», CG 139) e social («nas portas dos ricos, / nas portas dos probes», CG 139).

6 O tema dos alimentos, máis alá do dito na nota ao pé anterior, merecería o seu desenvolvemento dun xeito autónomo incluso en Cantares gallegos xa que ofrece unha paraxe onde deterse máis. Excede os obxectivos destas páxinas facer ese estudo, pero serve como mostra a liña debuxada e tamén unha mínima achega ás observacións de Marina Mayoral ao redor do costumismo: «Muy frecuentemente encontramos referencias a comidas. A la meniña gaiteira que inicia los Cantares le ofrecen para que cante manjares típicos de la tierra; algunos, propios de la gente humilde, como los bolos do pote, que son bollos hechos con harina de maíz y cocidos en el caldo, o las papas ("gachas"), o el pan mojado en vino; otras son comidas más ricas, como las torrijas con miel. Las patatas asadas con sal y vinagre creo que son las que se hacen sobre las brasas, a veces en el campo, apovechando la quema de las hojas de la planta, al recolectar las patatas sembradas...» (Mayoral 2008: 268). O estudo segue polo terreo da vestimenta, á que aludimos no noso enfoque só aos efectos de deternos nos intercambios que fan a cuestións de transmisión oral literaturizada. 
O poema 3 (CG 142-148) funciona como unha posta en que a muller maior recoñece o mérito da rapaza nova. Este intercambio discursivo actúa como unha constatación, como para solidificar nesa posta dialóxica o recońecemento de que, ao longo do libro, se estará enunciando desde unha voz autorizada, recońecida pero nova. Isto non é menor. Contrariamente ao lugar atribuído tradicionalmente na oralidade á sabedoría, destinada polo xeral a levar o fío da transmisión, é unha «menińa gaiteira» a que colle o fío nesta ocasión; pero esta condición non se presenta sen máis. É moi pertinente que exista este encontro en que dúas xeracións ben distantes no cronolóxico se atopan fronte a unha problemática común. O eixe de cantar a Galicia supera todo corte por idade — malia que en cada banda de idade adquira as súas características - e, pola súa vez, trae unha inversión pola que se anova a voz dunha Galicia que está precisa de expresión e de convocar unha forza potenciada nesa expresión.

Nos intercambios verbais nos que podemos recoñecer dúas posicións diferenciadas polo seu capital de experiencia, o lugar de alguén que procura facer unha aprendizaxe sobre outro suxeito ofrece un punto de vista anovador. Estes intercambios non constitúen unha típica escena de transmisión. É como repensar os puntos estipulados de emisión e recepción. A complexidade da experiencia na terra, no cotián e no que sae un pouco das vivencias diarias, encárnase en escenas de diálogo novas e que hoxe, desde unha análise da oralidade focalizada na transmisión, brinda a posibilidade de vermos outro espazo en que Cantares gallegos é revolucionario, pois desnaturaliza e resignifica as vías máis doadas ou transitadas, as vías en que é lóxico que alguén que viviu máis se faga cargo de cantar as penas e de falar desde o feito vivido e sufrido.

O poema 5 («Miña Santiña, / miña Santasa...», CG 153-159) propón unha instancia receptora que, lonxe de aceptar sen miramentos o consello da santa como lugar da sabedoría, se rebela e manifesta o seu desexo de transgredir o perímetro dos labores da costureirińa para dar renda solta á liberdade asociada ao movemento do baile. A consideración pormenorizada deste poema, así como a subversión do cancioneiro tradicional galego, ten un tratamento exhaustivo en Anxo Angueira (2011a e 2011b, entre outros), quen explora detidamente o artificio, a reelaboración e a transgresión cos que Rosalía redirixe ou subverte o contido do material popular do que parte. É especialmente significativo o traballo que Angueira fai ao 
redor da figura das costureiras (2011a: 7 e ss.) e a concentración na mudanza da forza discursiva que observa na rapaza deste poema:

Rosalía dálle voz e independencia á moza, e toda a falta de inxenuidade que se queira nos seus xogos equívocos, para ser ela, a irreverente costureira, a que venza fronte á cultura represora (tradicional e relixiosa), que argallou durante séculos as pesadas e infernais advertencias (Angueira 2011a: 35) ${ }^{7}$

Manuela quere "fuxir da lama». A Rosa do comezo de Cantares gallegos cede a súa voz a Manuela, a costureiriña que quere aprender a bailar, pero a transmisión que se dará non terá que ver coa súa demanda. $\mathrm{O}$ consello da sabedoría virará o foco para que a rapaza volva ao deber, aínda que non só polo deber mesmo; farao, esencialmente, para o recońecemento das limitacións que, de non ser consideradas e sopesadas, poderían traer males e padecementos aínda maiores. Nunha dimensión de evidente plano denotativo, o contido do que a santa transmite é unha advertencia de base para preservar a rapaza do engano de alguén, pero, en verdade, esa transmisión xa se producira, dalgún xeito, posto que fora xustamente un mozo quen lle fixera á rapaza a primeira advertencia polo seu descoido: «nin teño agulla, / nin teño liña, nin dedal teño, que aló na feira / robóumo un majo / da faltriqueira, / decindo: "As perdas / dos descoidados / fan o lotiño / dos apañados"» (CG 156). Significativo estalido das lińas esperadas en materia de transmisión: o ensino chegou

7 O desenvolvemento deste tipo de subversións, en particular cando se toma a figura das costureiras, ten o seu sitio nos imprescindibles traballos do autor citado. Así como non nos detivemos na cuestión dos alimentos e a súa complexidade para unha análise antropolóxica, tampouco afondaremos con exhaustividade nesta lińa. Cómpre, porén, cara á consideración da transmisión en si, lembrar algunhas conclusións que sobrevoan a lectura da presente proposta: «O cantigueiro popular ofrece unha visión das costureiras tremendamente negativa e, polo visto, son obxecto dunha sátira plural: finiquitas, desertoras do campo e da cociña, preguiceiras, doadas para o sexo... O poema de Rosalía de Castro recolle, efectivamente, todo este contexto pero revírao de tal xeito que se converte nun poema, ó noso entender, defensor da costureira, da súa clase e da súa dignidade. O texto defende claramente a aspiración da moza a ter unhas mans coidadas, a fuxir da lama: é un poema de temática SOCIAL que se posiciona a prol dos que aspiran a saír da miseria e contra a inmobilidade clasista. Pero tamén o texto defende a tódalas mozas que deciden ir bailar e divertirse sen lles importa-la "honra", libremente: é un poema, xa que logo, tamén FEMINISTA, no que se beirea, segundo a nosa lectura, a defensa do xa chamado na época "amor libre". Como a inmobilidade clasista e a represión contra os desexos vitais da rapariga están representados por unha santa, pola relixión, a rebeldía final da costureira adquire unha dimensión intensamente ANTICLERICAL» (Angueira 2011a: 35, maiúsculas no orixinal). 
dun descoido que xa se producira e veu dun rapaz da vila e non dunha posición autorizada ou sacralizada. Malia que ese tipo de tratos sexa criticado pola «Santińa», son dúas as liñas que advirten á rapaza e, máis alá do nivel denotativo enunciado antes, o máis profundo de ambas as advertencias é o que elas teñen de predestinación pola orixe socioeconómica da rapaza. Non se trata dun típico ensino abocado á preservación da honra; é tamén a queixa resignada polo aparente determinismo ao que os tempos de desigualdade e marxinación levan os sońos novos. A sorpresa da alarmada conselleira adquire a maior forza nos versos «ised'as que dormen / antr'o centeo! / ¡Fuxir da lama / quen naceu nela!» (CG 154-155). Deste xeito, a muller sabia, a «Santińa» invocada nunha devoción de intimidade familiar, tenta salvagardar a dignidade da dama nunha resposta que non encaixa co requirimento da rapaza. Despunta o desexo de pońer en movemento o corpo case como unha vocación, como un chamado que a convida a facer algo con paixón, non polo mero feito da diversión, senón case como un rito iniciático. Hai na demanda de ensino un pedido explícito que pasa sobre as ansias de diversión e que aspira a liberar o corpo e burlar os límites de pertenza aos que están atados os pobres, e tamén os límites duns mandatos sociais e de xénero que encadean o sentir da rapaza. $\mathrm{O}$ dentro e o fóra pasan a ser moito máis que delimitacións espaciais do baile; son, sobre todo, a ocasión de saltar límites: «Faláime sólo / das muiñeiras, / daquelas voltas / revirandeiras / daqueles puntos / que fan agora / d'afora adentro, / d'adentro afora» (CG 155), así como tamén se saltan os compartimentos estancos dunha escena da transmisión tradicional e estática.

A negación da transmisión dun saber por parte da santa tan particular xustifícase sobre a base do perigo que entrańa o abandono dos deberes domésticos e o trato en espazos vinculados a certa levidade. $\mathrm{O}$ intercambio, lonxe das tradicionais escenas literarias que versan sobre dous extremos encarnados por suxeitos que entrañan o saber e a falta de saber sobre algunha materia, é, neste caso, aparentemente frustrado, porque o que prevalece é xustamente a resistencia a unha aprendizaxe que podería ser sinxela, pero que pode albergar consecuencias adversas e indirectas respecto do saber en si mesmo.

A materia do saber que hai que transmitir adelgaza nun contexto sociocultural que instala a pantasma de séculos de marxinación e esquecemento, de desigualdades sociais e de xénero. A negativa ("Costureiriña, n’hei de ser, n’hei, / quen che deprenda / tan mala lei», CG 158) e o anoxo que trae para a rapaza en canto receptora 
frustrada ( ——iAi, que Santasa! / ai, que Santona, / ollos de meiga, / cara de mora! / Pór n’hei de pórche / os meus pendentes, / pór n’hei de pórche / o meu collar, / xa que non queres, / xa que non sabes / adeprenderme / a puntear», CG 158-159) parece encubrir un tácito acordo de comprensión mutua. Nese acordo, a que se nega a transmitir unha aprendizaxe entende pero teme as consecuencias e prefire resgardar a rapaza (e manter así a orde estabelecida). A rapaza condena a santa, pero faino con alcumes de escasa carga de furia. A muller nova parece defenderse tras o «non sabes». Antes disto, a idea era só que a muller sabia non quería transmitir algo, non era que non sabía como. A pasaxe do «non queres» ao «non sabes» interpón unha tregua máis que unha intensificación do anoxo. Isto opera como unha resignación, un engano para si mesma, que de certo xeito incorpora e fai propias as razóns esgrimidas pola santa ao longo de todo o poema. Non cae polo seu peso a sabedoría precavida da Santiña, pero resplandece, no gris panorama en que se nega a música e o baile, a paixón dunha rebelión que é capaz de cuestionar o universo dado.

E así como o rapaz do poema 5, que advertía sobre as perdas e as súas consecuencias, o gaiteiro do poema 8 (CG 174-176) brinda tamén unha aprendizaxe grazas a unha transmisión en discurso directo. Pero tamén neste caso a transmisión é $a$ posteriori, cando xa para moitas rapazas é tardía a advertencia. O consello, doutra banda, dáse non de xeito directo; prodúcese, polo contrario, nunha ampla e difusa terceira persoa de plural: «I el que, d'amores sedento, / quixo a todas engańar, / cand'as veu dimpois chorar, cantaba nas mañanciñas: / -Non sexan elas toliñas: / non veñan ó meu tocar» (CG 176).

É certo que a reflexión do «repoludo gaiteiro» polas consecuencias dos seus actos chega tarde para moitas, pero tamén ocorre que se eterniza a recomendación nun lamento que xa non se refire aos momentos particulares do que cantaba en cada mañanciña («tiña costum’en cantar / aló pola mañanciña: / —Con esta miña gaitiña / ás nenas hei d'engañan», CG 174, e outros versos en que se reitera «aló pola mańancińa”). Agora son todas as mańancińas («cantaba nas mańancińas», CG 178), nunha continuidade que parece querer superar os actos particulares e resignar a sede de amores, aínda que dun xeito oblicuo e traballoso.

Outra das aprendizaxes que se presenta de xeito especial e que non semella ter unha doada posta en práctica e nin sequera unha aceptación é a do poema 9 (CG 177-181), que compete ao que o cura sinala como pecado: «Díxome nantronte o cura / qu'é pecado... / mais aquél de tan fondura / ¡cómo o facer desbotado?» (CG 
177). O poema abre e pecha co que intentou transmitir o cura («Por eso, anqu’o cura dixo / qu'é pecado, / mal que tanto mal me fixo / nunca o daréi desbotado», CG 181), pero iso non foi dabondo porque, en realidade, esas estrofas rodean algo que escapa á racionalidade e a un mandato pechado, monocorde e sobre todo sen xustificación do cura (xa que o aludido é unha prohibición, que é un enunciado sen fundamento, que é mera aserción).

Ao tempo que medra a intensidade coa que a voz poética deste texto manifesta o seu sentimento por Jacinto, medra tamén a sensualidade das imaxes e faise cada vez máis feble a resonancia das palabras do cura. A liña discursiva do cura é, de feito, literalmente retomada pola voz que conduce o poema 9 para quedar nunha mera mostra de falta de forza ${ }^{8:}$ «QQue é pecado..., miña almiña! / Mais que sea, / ¿Cál non va, s'é rapaciña, / buscando o que ben desea?» (CG 178). Os puntos suspensivos e a exclamación en que se insiren as palabras do cura desestímanas no mesmo acto de fala polo que son traídas a conto. Segue a isto unha posta en dúbida pola que se volve instalar o ton de reclamo da costureiriña do poema que xa analizamos: é natural a aparición deses desexos, e máis natural aínda é que xurdan con especial forza na mocidade. Neste caso, ademais e como anticipamos, temos o aditamento de que o xuízo do cura é un mero enunciado que se considera baleiro e as outras voces que transitan polo poema son só rumores, expresións pouco precisas dunha terceira persoa dun plural máis ben impersoal e que xulga sen moito coñecemento do asunto ("Din que parés lagarteiro / desprumado», CG 178). Baléirase de contido a interposición desas voces e converxen para resaltar a instancia receptora da voz nova na que prevalece a expresión do desexo xa que os argumentos interpostos, os «consellos» (que neste caso son prohibicións ou xuízos subxectivos) ou ben non se

8 Para afondar en cuestións de forza e de como a imaxe da muller galega encarna un modelo que cuestiona os parámetros nese senso, cómpre deterse na análise de Catherine Davies, especialmente na súa consideración dun libro da antropóloga inglesa Annette Meakin: «Woman in Transition [...] trata da muller na transición cara á modernidade e está escrito desde unha óptica feminista moderna. Os capítulos dedícanse ás raparigas, ao matrimonio, á maternidade, á viuvez, aos clubs e sindicatos, á muller obreira e da media clase, ao socialismo, ao anarquismo, á psicoloxía da muller e á coeducación. Toda esta temática examínase a través das mulleres de diversos países: Alemaña, Francia, Turquía, Rusia, Finlandia e España. [...] O máis interesante deste libro [segue a dicirnos Davies] é a sección titulada "Amazonas españolas", un eloxio non das españolas senón das galegas. Meakin utiliza o exemplo da muller galega para demostrar a súa teoría feminista de que a forza física e mental da muller é igual á do home» (Davies 2012: 18). Cómpre ter en conta esta perspectiva máis alá de que a paraxe teórica que adoptemos non sexa explicitamente algunha das vertentes da teoría feminista. 
desenvolven nunha xustificación, ou ben consisten en apreciacións febles e dependentes dun punto de vista respecto dunha apreciación física.

O poema 20 (CG 219-224) preséntanos outro exemplo dunha particular apropiación dos modelos de transmisión. Se hai unha canle especialmente permeable para a transmisión é toda aquela que pertence a xéneros tradicionais de cantos e contos para bebés e nenos. Cando se trata dun xénero como o das cancións de berce, no que os destinatarios son tan pequenos, é difícil propor a transmisión en termos de típica comunicación duns contidos, pero si que hai formato de comunicación e a forza da reiteración do xénero fixa os contidos nunha memoria cultural, que supera o máis inmediato da memoria comunicativa9. Agora ben, a «canción de berce» que podemos atopar no poema número 20 non pode ser nomeada así sen máis aclaración, posto que constitúe máis ben unha inversión do que se agarda dunha canción de berce (ou das que, polo xeral, máis conscientemente escollemos dentro dun amplo repertorio cando apuntamos a un contido tranquilizador e previsible que apunte aos «doces sońos» dos nenos). O que se pode ler ata como «anticanción de berce» son as palabras da voz poética que leva desde o comezo o texto, e que podemos atribuír á mencionada Rosa que, neste caso, é xa maior e está a coidar dun neno pequeno (ou simplemente a espialo). O contido convulsiona o xénero porque xa desde a primeira estrofa, que son os versos populares que se incorporan en cursiva á creación de Rosalía, se advirte que o tema se funda nas carencias e non en soños azuis e calmos desexos dun durmir relaxado xa que aparece a pantasma que atravesa todo o libro: a fame: «Ora meu meniño, ora, / ¿Quén vos a de dar a teta, / si túa nai vai no muiño, / e teu pai na leña seca?» (CG 219). A nai, que está

9 Cómpre considerar neste punto o par dicotómico «memoria comunicativa-memoria cultural» en termos de Jan e Aleida Assmann, que formularon o concepto de «memoria comunicativa» para redefinir «[...] el aspecto social de la memoria individual que definiera Halbwachs. Dicha memoria [la memoria comunicativa] pertenece al ámbito intermedio que se da entre los individuos, y surge en el contacto entre los seres humanos» (Assmann 2008: 19). Este tipo de memoria desaparece no ciclo de tres xeracións (Assmann 2008: 24). A memoria cultural, pola súa banda, é conceptualizada como «[...] un caso especial de memoria comunicativa. Tiene otra estructura temporal: si pensamos en el típico ciclo trigeneracional de la memoria comunicativa como un espacio sincrónico, la memoria cultural, con sus tradiciones que se retrotraen a un pasado lejano, conforma un eje diacrónico» (Assmann 2008: 25). Tomando en conta o problema das traducións, cabe aclarar o que indica Marianne Hirsch sobre os conceptos de Assmann: "Assmann uses the term "kulturellesGedächtnis" ("cultural memory") to refer to "Kultur" an institutionalized hegemonic archival memory. In contrast, the Anglo-American meaning of "cultural memory" refers to the social memory of a specific group or subculture» (Hirsch 2008: 110). 
traballando, non pode estar no momento en que a fame ataca o neno e a muller que está preto del non ten leite que o satisfaga. As cancións de berce, aínda as que tratan cuestións sociais e económicas que se poderían pensar como alleas aos nenos, que as hai ${ }^{10}$, inclúen, polo menos, unha luz de esperanza, que adoita estar vinculada a necesidades básicas, como a mantenza ${ }^{11}$.

Neste poema-canción rosaliano, ata que aparece outra presenza (e outra voz), domina a desesperanza máis extrema, a que nin sequera garda espazo para unha licenza poética coa que enganar o neno: «Mais, jai, que noite che agarda! / ¡Mais, ai que noite che espera! / Qu'anque dúas fontes teño, / estas fontiñas non deitan» (CG 219). É certo que non necesariamente temos que pensar nunha verbalización aberta na que Rosa estea a dicir en voz alta e tentando transmitir palabra por palabra a triste situación ao meniño, pero, polo menos, hai que admitir unha transmisión figurada onde non se lle pide ao pequeno que durma, como é habitual que ocorra en contextos semellantes; pídeselle que rece, porque non parece haber moito máis por facer. Nun intre, a primeira persoa singular que guía a primeira parte do poema, a que se lle atribúe a Rosa («Así se espricaba Rosa» (CG 220), chega a temer e a anunciar ao neno a súa propia morte polo frío e fame: «Sin cobirtor que te cruba / nunhas palliñas te deitan / e neve e chuvia en ti caen / por antr'as fendidas tellas. / E silba o vento que pasa / polas mal xuntadas pedras, / e cal coitelo afilado / no teu corpiño se ceiba. / ¡Ai, cando veña a túa nai! / ¡ai, cando ch’a túa nai veña! / cal te topará, meniño, / frío com'a neve mesma, / para chorar sin alento, / rosiña qu'os ventos creban...!» (CG 220). Non hai mención da morte, pero o coitelo afiado e o frío extremo do corpo fan resoar esa idea. Cando sobrevén o sobrenatural no poema, e no recinto onde está o neno, asistimos á transformación do berce ( $\mathrm{Xa}$ non dorme en probe cuna, / qu'outro berce lle fixeran», CG 222) e á mudanza da canción. A voz da Virxe que se achega para alimentar o neno é agora a que no seu canto anuncia que será ela quen lle dará o peito e dá volta á carga negativa dos presaxios.

10 Un dos exemplos máis destacados en Latinoamérica é o da canción «Duerme, duerme negrito", do poeta chileno Víctor Jara e popularizada na Arxentina especialmente na voz dos cantantes populares Mercedes Sosa e Jairo.

11 Por exemplo, na canción aludida na nota anterior, atopamos promesas como: «Duerme, duerme negrito / que tu mamá está en el campo, negrito. / Te va a traer codornices para ti. / Te va a traer mucha cosa para ti. / Te va a traer carne de cerdo para ti». A nai está traballando en condicións de explotación, porén, a voz poética transmítelle ao neno que ela vai traer o sustento. 


\section{CONCLUSIÓNS}

Os poemas analizados presentan unha transmisión dislocada que mostra outro dos xeitos en que Rosalía de Castro introduciu cambios e múltiples capas discursivas no que se coñecía como un terreo máis ou menos previsible. No caso desta proposta de lectura, ese terreo é o dos intercambios xeracionais que están implicados na transmisión oral feita texto. Trátase de escenas que, como vimos, botan man do popular e especificamente dunha estrutura de diálogo cotiá que explota en diversas traxectorias. Deste xeito, percorremos variacións ao redor das escenas de transmisión que brindan unha posibilidade de poñer en cuestión o que se agarda dun consello, dunha aprendizaxe ou dunha advertencia. Dunha banda, temos casos en que a presunta pasividade da instancia da recepción se rebela; doutra banda, por exemplo, temos pasaxes en que a transmisión expresa un baleiro que fai que se innove, mesmo nun xénero como a canción de berce, e que as voces desempeñen un rol fundamental nas mudanzas producidas.

A interposición das ferramentas teóricas alleas ao contexto de enunciación das voces que interveñen nos poemas escollidos, lonxe de apuntar a un procedemento que non teña en conta as precisións de lugar e tempo, apunta máis ben a ver como a riqueza de Cantares gallegos segue a albergar a achega de perspectivas que parten de tratamentos recentes, que botan man da historia cultural, da antropoloxía ou da ficcionalización da oralidade, pero que atopan estas vías de entrada nun texto que ten a permeabilidade para albergalas. No século XxI, Cantares gallegos segue a ofrecer espazos nas súas capas que teñen a potencialidade de dar cabida a novas lecturas e, fundamentalmente, á formulación de novas preguntas. 


\section{REFERENCIAS BIBLIOGRÁFICAS}

Angueira, Anxo (2011a [2002]): «Un poema de Rosalía de Castro», A Trabe de Ouro, 49, 13-38. Reedición en poesiagalega.org. Arquivo de poéticas contemporáneas na cultura (http://www.poesiagalega.org/arquivo/ ficha/f/946).

Angueira, Anxo (2011b [2008]): «Os cantares populares en Cantares gallegos», Revista de Estudos Rosalianos, 3, 39-51. Reedición en poesiagalega.org. Arquivo de poéticas contemporáneas na cultura (http://www.poesiagalega. org/arquivo/ficha/f/1104).

Assmann, Jan (2008 [2000]): Religión y memoria cultural. Diez estudios. [Trad. Marcelo G. Burello e Karen Saban]. Bos Aires, Lilmod.

Benjamin, Walter (1986 [1936]): «El narrador», en Sobre el programa de la filosofía futura. [Trad. Roberto Vernengo]. Barcelona, Planeta-Agostini, 189-212.

Burgos Debray, Elizabeth (2002): «Memoria, transmisión e imagen del cuerpo. Variaciones y recreaciones en el relato de un escenario de guerra insurgente», Nuevo Mundo Mundos Nuevos, 2 (http://nuevomundo.revues. org/537). [Última consulta: 13/10/2014].

Carballo Calero, Ricardo (1952): «Arredor de Rosalía», en VV. AA., 7 ensayos sobre Rosalía, Vigo, Galaxia, 17-39.

Carballo Calero, Ricardo (1959): Contribución ao estudo das fontes literarias de Rosalía. Discurso de ingreso na Real Academia Galega lido o día 17 de maio de 1958 seguido da resposta de Ramón Otero Pedrayo, Lugo, Ediciones Celta.

Carreño, Antonio (1986): «El discurso de la tradición: los Cantares gallegos de Rosalía de Castro», en Actas do Congreso internacional de estudios sobre Rosalía de Castro e o seu tempo, Santiago de Compostela, Consello da Cultura Galega / Universidade de Santiago de Compostela, I, 191-200.

Castro, Rosalía de (1995 [1863]): Cantares gallegos. [Ed. de María Xesús Lama].Vigo, Galaxia.

Davies, Catherine (2012): «Rosalía de Castro e a antropóloga feminista inglesa Annette Meakin», Grial, 194, 16-19.

Hirsch, Marianne (2008): «The Generation of Postmemory», Poetics Today. 29:1, Porter Institute for Poetics and Semiotics, 103-128.

López-Casanova, Arcadio (1995): «Estudio de la obra poética», en Arcadio López-Casanova (ed.), Rosalía de Castro. Antología poética (obra en gallego y en castellano), Madrid, Alhambra Longman, 26-73.

Mayoral, Marina (2008 [1974]): La poesía de Rosalía de Castro, Alacant, Biblioteca Virtual Miguel de Cervantes.

VILAVEdRa, Dolores / María do Cebreiro RÁbade (2012): «Novas olladas sobre Rosalía de Castro. Limiar», Grial, 194, 13-15. 
